\title{
Subjecting optics and photonics text materials to a morphing process
}

Darrell Hull, Arthur Guenther, Leno Pedrotti

Darrell M. Hull, Arthur H. Guenther, Leno S. Pedrotti, "Subjecting optics and photonics text materials to a morphing process," Proc. SPIE 3190, Fifth International Topical Meeting on Education and Training in Optics, (8 December 1997); doi: 10.1117/12.294367

Event: Fifth International Topical Meeting on Education and Training in Optics, 1997, Delft, Netherlands 
Subjecting Optics and Photonics Text Materials to a Morphing Process

Darrell M. Hull, Arthur H. Guenther ${ }^{\dagger}$, Leno S. Pedrotti

Center for Occupational Research and Development

P.O. Box 21689, Waco, Texas 76702-1689

\begin{abstract}
At present, previously developed curriculum materials designed to teach the technology of Lasers and Electro-Optics for two-year postsecondary students are becoming outdated. In an effort to update technology-oriented curricula for the new and emerging applications of photonics, the authors are proposing a systemic process that would facilitate the interaction of educators in an innovative electronic format. The morphing process is NOT a listserve, but an established set of curriculum materials in Laser/Electro-Optics that in print contain over 1900 pages and an excess of 1300 illustrations, all placed on the World Wide Web that would allow access to faculty only. The faculty will be allowed to make peer-reviewed changes to the curriculum via an E-mail submission process and submit ideas for lecture and laboratory techniques that will be hyperlinked to specific parts of the curriculum. The curriculum and the process will be available to optics/photonics faculty world-wide as recently proposed in a 3-year project with the U.S. Department of Education.
\end{abstract}

Key words: faculty, curriculum, photonics, optics, world wide web, morphing

\title{
1. Introduction
}

Community colleges and technical schools that prepare students in their $13^{\text {th }}$ and $14^{\text {th }}$ years of study throughout the United States are in need of a curriculum to replace the existing Laser/Electro-Optics Technology (LEOT) curriculum materials that are presently in place. These materials, developed in the 1970s and revised somewhat every five years or so, remain outdated. A new curriculum should include the broader, newly emerging field of photonics technology. A national project has been proposed that will correct this need for modern materials as well as demonstrate and pioneer a process of transforming technology-sensitive curricula via the Internet. Up-to-date curricula are needed to educate students for technical careers, especially for the technicians who serve the field of photonics that is presently undergoing a technological and economic explosion. The project will evaluate the ability of a "morphing" 1 process to rapidly and effectively update technical curricula through an interactive World Wide Web site. While the two parts of this project are separated for clarity, the two facets are intimately integrated. The morphing process will be used to update the LEOT curriculum. As the updated curriculum is developed, the ability of the morphing process to modify and maintain technical currency will be evaluated.

CORD made a significant commitment to ensure that the existing LEOT curriculum-developed with U.S. Office of Education funding, 1970-1974 - was revised periodically to reflect industry changes. A partnership of colleges, engineering professional societies, and business employers met with CORD annually to discuss trends in the industry. From these meetings, curriculum revisions were suggested and implemented, and CORD's staff developed close working relationships with the faculties of some 30 institutions offering the LEOT program. By the early nineties, it was evident that the LEOT materials were not meeting the needs of the emerging photonics industry. The need to change the LEOT curriculum to include photonics became evident. However, the traditional process for text revision does not react quickly enough to keep pace with the growing development in the photonics field. Faculty at the using colleges are expressing frustration with the low numbers of students enrolling in LEOT programs and the growing gap in technical skills needed for technicians in photonics.

In 1993, CORD received a grant from the U.S. Department of Education to develop one of the 22 pilot national skill standards - the standard for photonics. Photonics employers indicated the urgent need for well prepared new technicians. By 1994, the photonics skill standard was defined. Comparison of the skill standard with current LEOT associate degree

${ }^{\dagger}$ Currently at The Center for High-Technology Materials, University of New Mexico, Albuquerque, New Mexico 
programs revealed the need to update the existing LEOT course offerings as well as develop more photonics-intensive curricular material. Through a 1995 grant from the National Skill Standards Board, a curriculum framework is being designed for a broader technical core curriculum in the electromagnetic field. This framework will combine basic technical skills in electronics and lasers/optics into a cluster to begin the preparation of technicians for later specialization in photonics or other electronics fields.

While the development of a broader, technical core curriculum is a necessary first step in a major overhaul of the LEOT curriculum, photonics industry employers and colleges need a curriculum to teach photonics now. A new curriculum development process is needed to enable educators to react quickly to provide the skills industry needs. The colleges that offer these programs need a process for effective dialogue with other faculty, for adjusting curriculum, for responding to local business aspects, and for meeting accreditation standards. Traditional methods for writing or revising textual materials are not time efficient, and the quality of interaction required by faculty from colleges throughout the U.S. is not logistically practical. This paper offers a solution to these immediate concerns.

\section{Background}

The LEOT curriculum, 1900 pages in ten texts, has been widely used by community colleges in the U.S. for 25 years. However, as noted, the outdated LEOT curriculum is inadequate for educating technicians for the modern photonics field. Demand for workers with broader technical skills coupled with recent impetus given by the 1995 National Photonics Skills Standard for Technicians (NPSST) indicates that community colleges are operating currently with an out-of-date curriculum.

The existence of antiquated curricula in rapidly evolving technical fields is especially evident in the laser/optics arena. In spite of the expertise and interest of secondary and postsecondary technology faculty, instructor input to curriculum development is often hampered by lack of an effective, timely, interactive communication structure, absence of a central informational clearinghouse, and limited time and capital resources. Dissemination of curriculum improvements made by teaching faculty has traditionally been slow, haphazard, and resource intensive. Since the mid-1970s, CORD and the approximately 30 schools offering the LEOT curriculum have attempted to maintain curriculum currency. However, traditional methods of curriculum revision cannot react quickly enough to rapidly evolving advances, leaving some portions of the curriculum 10 to 15 years behind the technology. A convenient and cost/time-effective process is needed to keep instructional materials current, accessible, and reflective of workplace trends.

In addition to a lack of marketplace currency and accessibility to faculty, technical curricula by their nature often hinder the involvement of women, ethnic minorities, and nontraditional students-the older, working, and/or single parent studentsprimarily through rigid formats and a presentation and setting of information insensitive to the background and experiences of today's postsecondary learner. To correct the status quo, we will develop a process to update an outdated LEOT curriculum and involve teaching faculty in a national, interactive morphing process to ensure currency of instructional materials and techniques while making the materials more attractive and accessible to nontraditional students on a timely basis.

\section{Documentation of Need}

In 1994, Angelo DePalma ${ }^{2}$ forecast that, "photonics is the foremost emerging technology that will affect all manufacturing industries over the next few decades, surpassing the combined impact of the transistor and the microprocessor."

The emerging need for a photonics curriculum is due to the convergence of the following factors:

- Photonics, defined as the generation, manipulation, transport, detection, and use of light and other forms of radiant energy whose quantum unit is the photon, is the key enabling technology of the 21st century. In communication, transportation, information, defense, precision manufacturing, biotechnology, and other industries of central importance to the economy, the role of microelectronics is being overtaken by photonics or combined with the field of opto-electronics. 
- Reports from the U.S. Departments of Commerce and Defense highlight photonics as critical to the nation's future.

- In 1993, the U.S. Department of Education highlighted the importance of the photonics industry by funding it as one of 22 National Skill Standards pilot projects.

- The U.S. White House Office of Science and Technology Policy has expressed strong public support for the photonics skill standard project. In March 1995, during a National Press Club release of the National Photonics Skills Standards for Technicians, Dr. Skip Johns, Associate Director of the White House Office of Science and Technology Policy, described photonics as fundamentally important to the nation's economic future and a key technology in support of the Information Superhighway.

- Demand for increased number of photonics technicians is not being met.

- The Optoelectronics Industry Development Association expects the U.S. photonics industry to approximately double in size every four years, achieving $\$ 500$ billion by $2013 .^{3}$ The demand for technicians with associate degrees in photonics will be driven by this growth.

- While industry demand for technicians is high, only a handful of schools offer some coursework in photonics and only seven schools offer AAS degrees in photonics.

- The central institutions offering AAS degree programs of study in photonics cannot find enough students to satisfy the demand from industry. Reports from these institutions at annual LEOT meetings indicate that over 99 percent of their students on average have been hired prior to graduation with starting salaries in excess of $\$ 25,000$ per year.

- The present LEOT curriculum is badly outdated.

- The 25-year-old LEOT curriculum focuses narrowly on lasers and older electro-optics subjects. Rapid development in lasers and widespread use of fiber optics, miniaturized sensors and detectors, laser diodes, modulators, and other innovations need now to be integrated into photonics technician education programs.

- The global competitiveness of a photonics industry depends critically on the availability of highly trained photonics technicians.

- Science and Engineering Indicators 1996 reveals that the United States had a 13.7 percent share in world exports of optoelectronics while Japan and Germany captured 22 percent and 24 percent, respectively.

- The current, dynamic photonics industry exists throughout the U.S., justifying federal support through education in order for the industry to thrive in the United States. See map in Figure 1. 


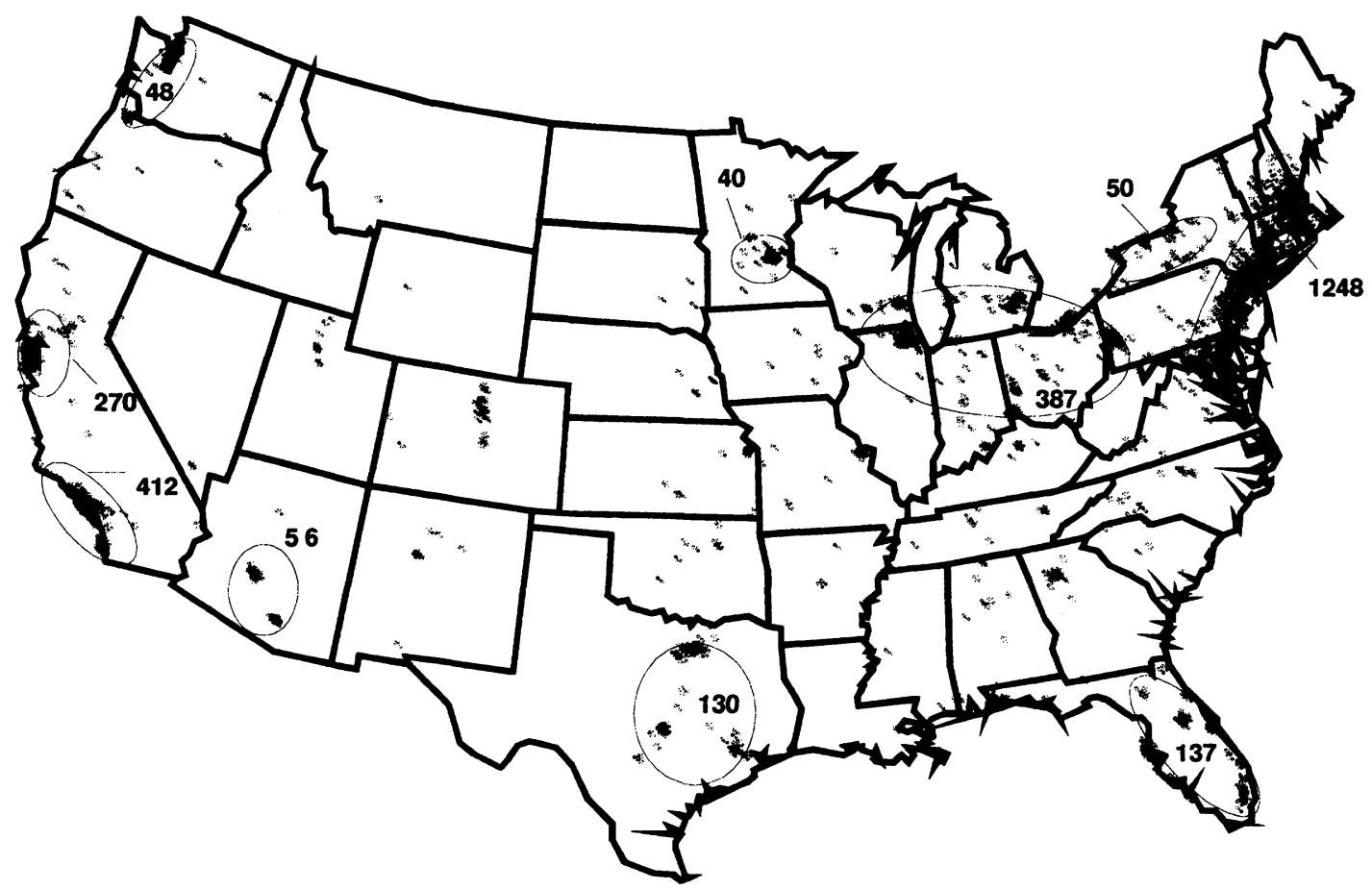

Figure 1. Global competitiveness of $3000+$ U.S. photonics companies depends critically on availability of highly trained photonics technicians

\section{Demographic changes require dramatic revisions in cultural assumptions of the curriculum.}

- Increasing presence of women, minorities, and immigrants in the workforce strongly indicates that the format and language of the old LEOT curriculum must be more culturally diverse and sensitive.

- Enrollment in U.S. colleges is experiencing a dramatic demographic change. Even in states with traditionally low minority populations like Connecticut, community college enrollment is already 68 percent African American or Hispanic and 62 percent female. The traditional white-male population is now a minority.

\section{Project Goals and Design}

This section describes in detail the two major goals of the project and lays out the design strategy for accomplishing these goals. The design strategy follows a 13-step "curriculum morphing flowchart." First the goals.

\section{Goal \#1: Updating a 25-year-old laser/electro-optics curriculum}

This project will use the photonics skill standard-an analysis of tasks and skills from photonics related industries-as the guideline for an ideal curriculum and the most technology-sensitive courses in the existing LEOT curriculum materials as a baseline resource to transform the LEOT instructional materials into a photonics curriculum. This curriculum will be released to photonics educators under the control of a diverse review team. When this release takes place, photonics educators will alter the materials they desire. From this starting point, project staff will work with community college faculty and business/industry representatives to develop a curriculum congruent with current practice and technology. Widespread participation in the project and dissemination of the printed materials will be made available via Internet. The project management realizes additional dissemination activities must take place in education networks outside the Internet to inform photonics educators of this new capability. This networking will be facilitated by employing existing partnership groups, the National Tech Prep Network, the National Coalition of Advanced Technology Centers, and the photonics industry 
partnerships formed during the identification of skills standards in the NPSST project-including professional societies in optics and photonics such as the International Society for Optical Engineering (SPIE) and the Optical Society of America (OSA).

\section{Goal \#2: Implementing a national interactive network to sustain curriculum currency}

This effort should produce valuable, updated curriculum materials for faculty, students, and the photonics industry. However, due to constant change and continued advancements in photonics, the "half-life" of "current" curriculum materials is short. The morphing process will be kept in place to maintain curriculum currency as technology advances, thereby creating a "living" curriculum. Unlike traditional textbook updates, which can take five years from revision to distribution, the proposed morphing interactive mechanism will enable photonics instructors and students to readily access the instructional materials necessary to keep students in step with advancing technology. Since faculty at all levels - secondary and two-year and four-year colleges - can participate in this accessible, interactive process, curriculum discontinuities between levels should decrease. A truly seamless curriculum for optics/photonics education should begin to emerge.

The project design is intended to simplify the lives of faculty and curriculum developers by enhancing their ability to communicate. Additionally, the morphing process uses a technological innovation that allows faculty to create a learning community among themselves whereby they can collaborate on effective techniques for the laboratory or classroom. The actual process to be followed for morphing is described in the Figure 2, a curriculum morphing flowchart: 


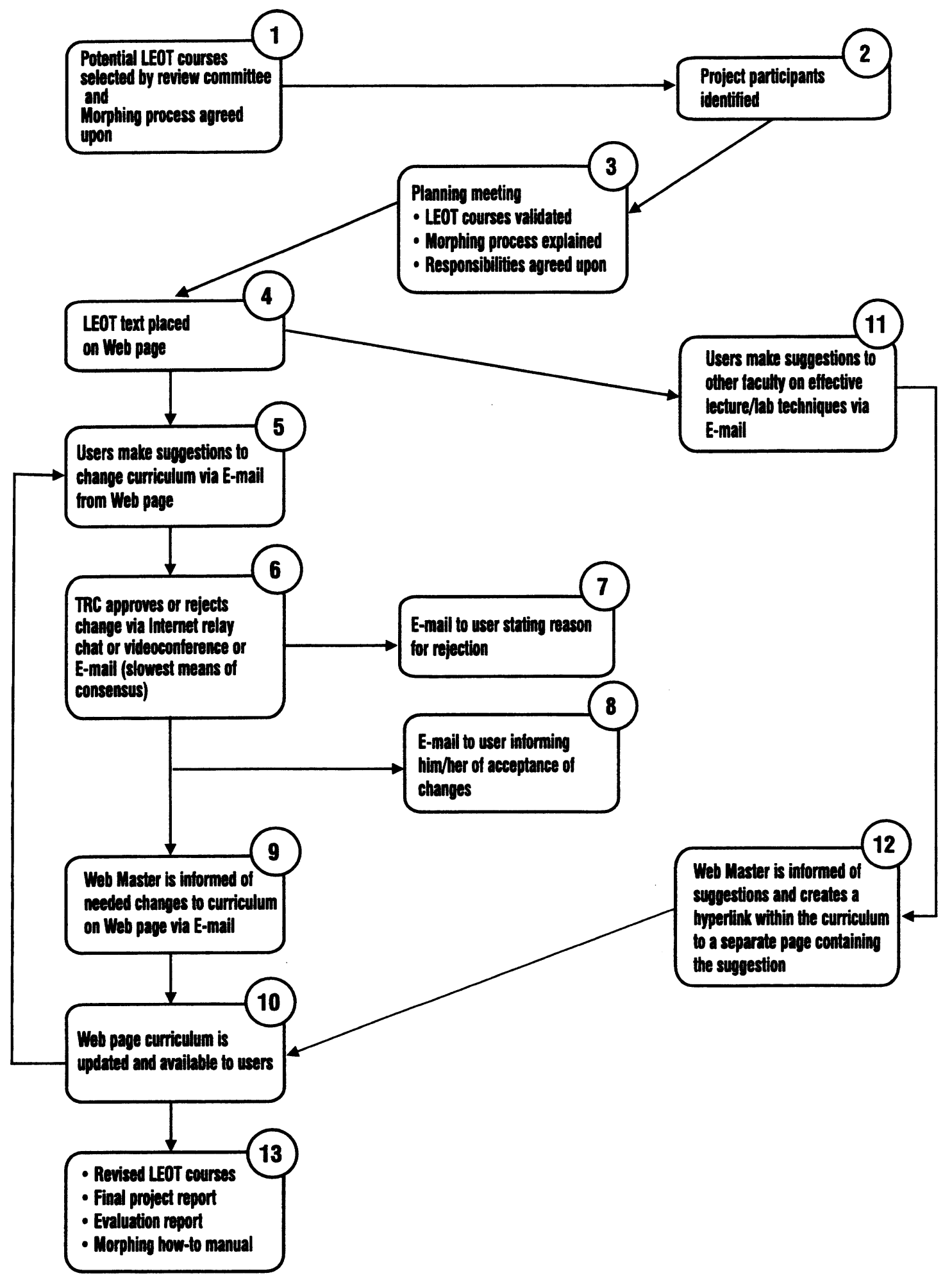

Figure 2. Curriculum morphing flowchart 
Steps 1-3 in the flowchart are perfunctory measures that must be taken to facilitate the process of curriculum morphing. Beginning with step 4, the curriculum must be reformatted in an electronic code called HyperText Markup Language (HTML) and given a Universal Resource Location (URL) on the Internet where it can be found. The person in charge of the HTML coding will be referred to as the "Web Master." Access to the curriculum will be made available to faculty and other selected interest groups (business/industry, professional societies, educators, national laboratories, and so on). Students will be excluded from access to the Web page so faculty may share ideas freely. This limited access can be obtained easily by faculty with an E-mail request for access to the page along with a phone number for verification. A "teaser" or sample page will be made available for anyone to access, and registered users will be given unique passwords for entry to the web master site. The HTML coding will be created to incorporate all illustrations and will resemble the format of the actual printed version of the LEOT material. See Web Page Illustration in Figure 3. The exception is that all the curriculum will be hyperlinked to allow for ease in locating various sections. These hyperlinks are common with almost any Web page, and serve also to prevent users from printing the entire text from their computers in a convenient format. CORD will reformat the material after conclusion of the project and reprint texts for students; the on-line faculty version will remain free.

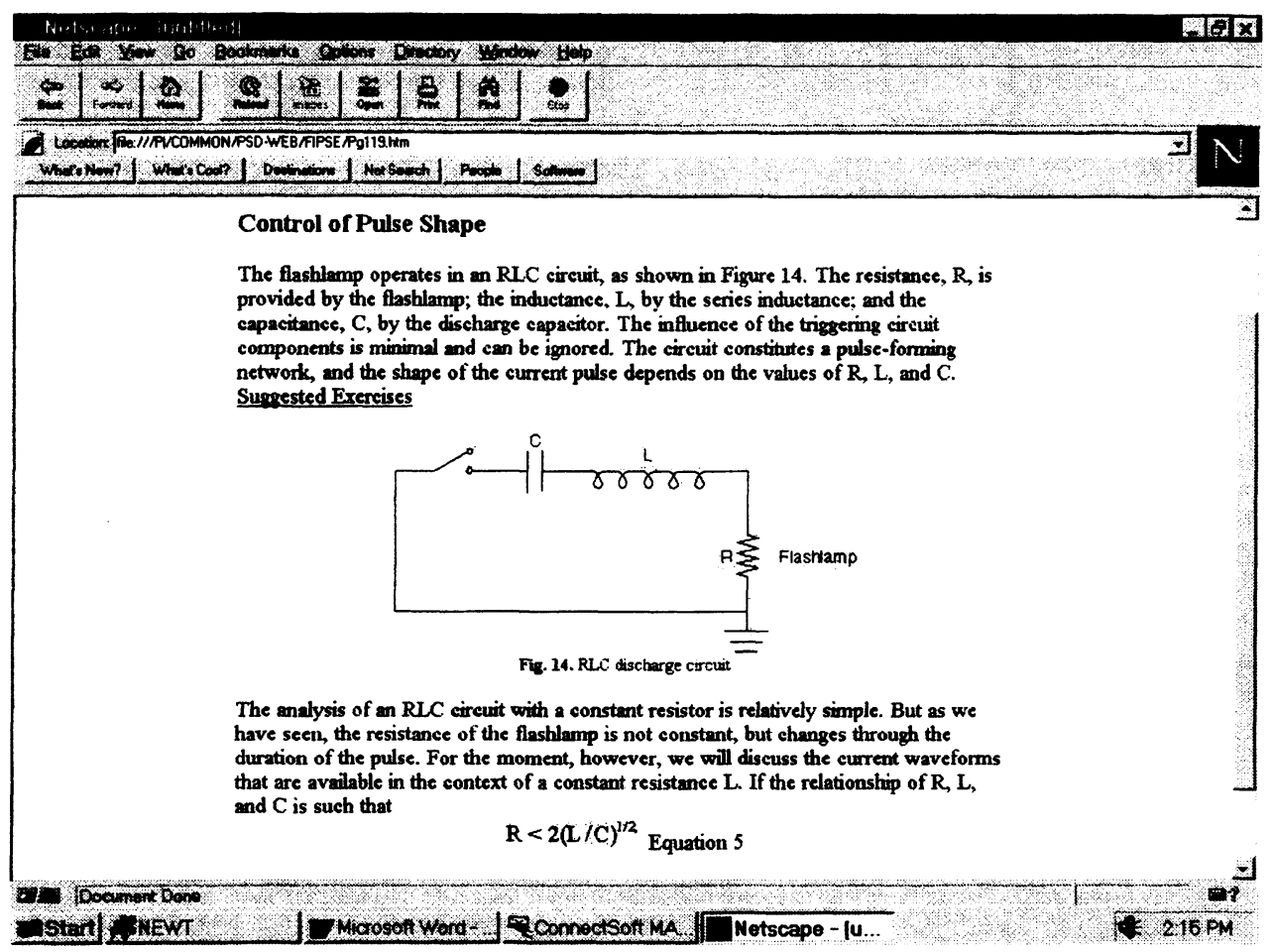

Figure 3. Web page illustration 1

As materials are being created in the HTML format, the CORD staff and the technical review committee (TRC) will make presentations and obtain coverage in technical publications within the industry to notify all interested parties about the new Web page and the morphing project to attract additional qualified users. When the page is ready, it will be placed on-line for users to make suggestions for corrections/changes to the curriculum or to post teaching techniques of value to other faculty. These helpful techniques will always be associated with a specific portion of the curriculum so that other faculty accessing these valuable ideas will know the context within which they may be used. As mentioned in steps 5 and 11 on the Curriculum Morphing Flowchart, users will be able to offer their suggestions using E-mail forms that are a part of the Web page. See Web Page Illustration 2 in Figure 4. 


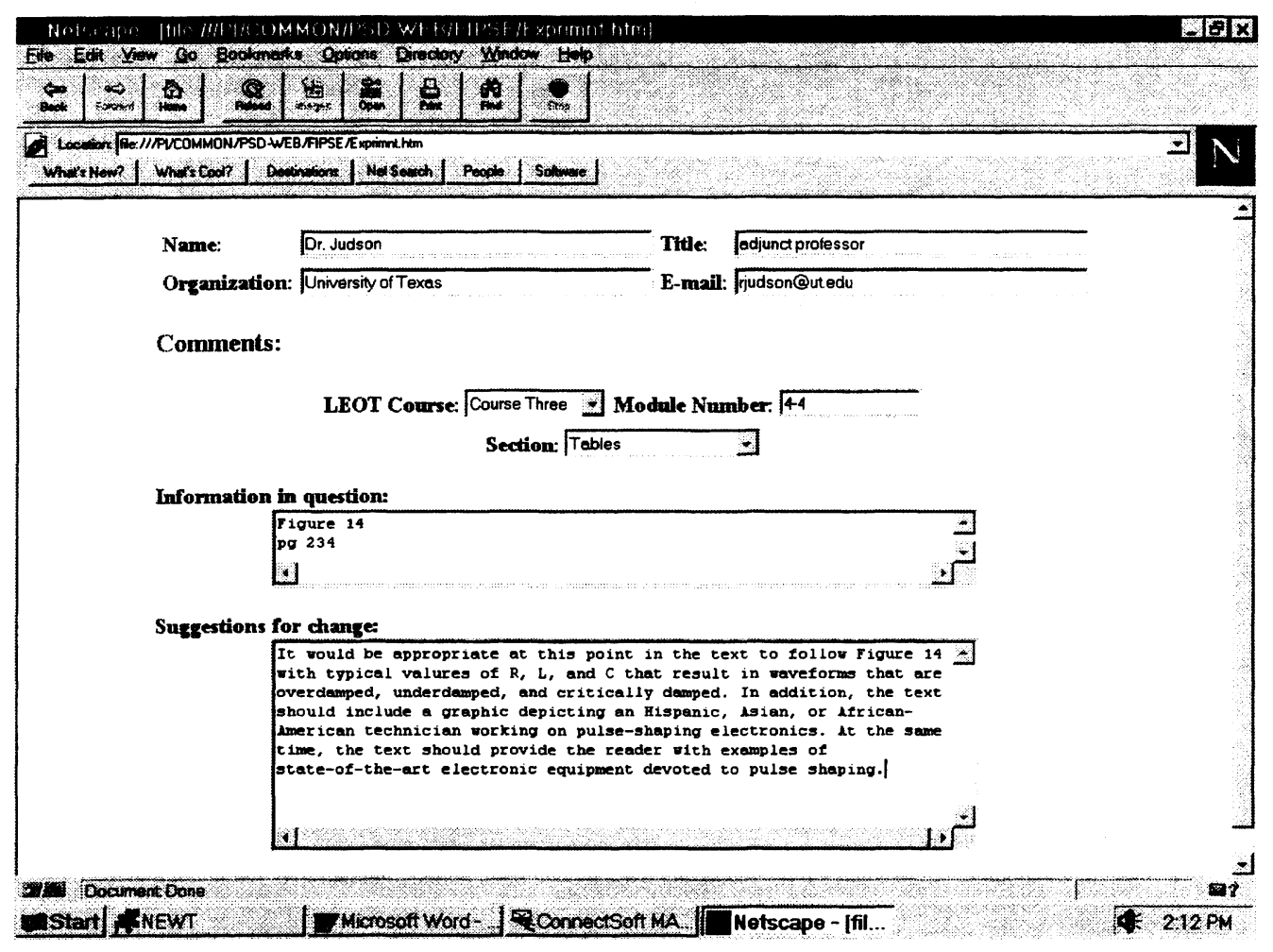

Figure 4. Web page illustration 2

The suggestions leave the Web page in the form of an E-mail that goes to members of the TRC. The TRC will evaluate all suggestions for appropriateness and do the following:

- Accept suggestion as stated;

- Accept suggestion with changes; or

- Reject suggestion.

In any case, the TRC will create a response as indicated in steps 7 and 8 on the flowchart and E-mail the submitter with thanks for the request and encouragement to submit again. In the event the suggestion is acceptable in some form, the TRC will E-mail the Web Master, indicating the change that should take place to the web page as stated in step 8 . When the change is made to the page, it will be seen immediately by all who access the page from that point on and be subject to additional changes from any user accessing the page. Thus we are creating a "living" or "morphing" curriculum since the Web page is never in a static mode when actively accessed by users.

As noted in steps 11 and 12 on the flowchart, one feature of the morphing curriculum process is that active, teaching faculty can submit ideas that facilitate learning in the classroom or laboratory. Recall your favorite professor from college; if only he or she could have shared techniques or the writings in the margins of his or her textbook with other professors. This sharing will have immediate impact on the quality of instruction across the nation, since these techniques or "tricks" are associated with specific portions of the curriculum. This feature should prove to be of considerable value for new teachers who are developing their classroom delivery technique. All of these teacher-aids will be listed on a separate, hyperlinked page and, if the submitter so desires, will include the submitter's E-mail address and name to encourage further follow-up from interested faculty. See Web Page Illustration 3 in Figure 5. 


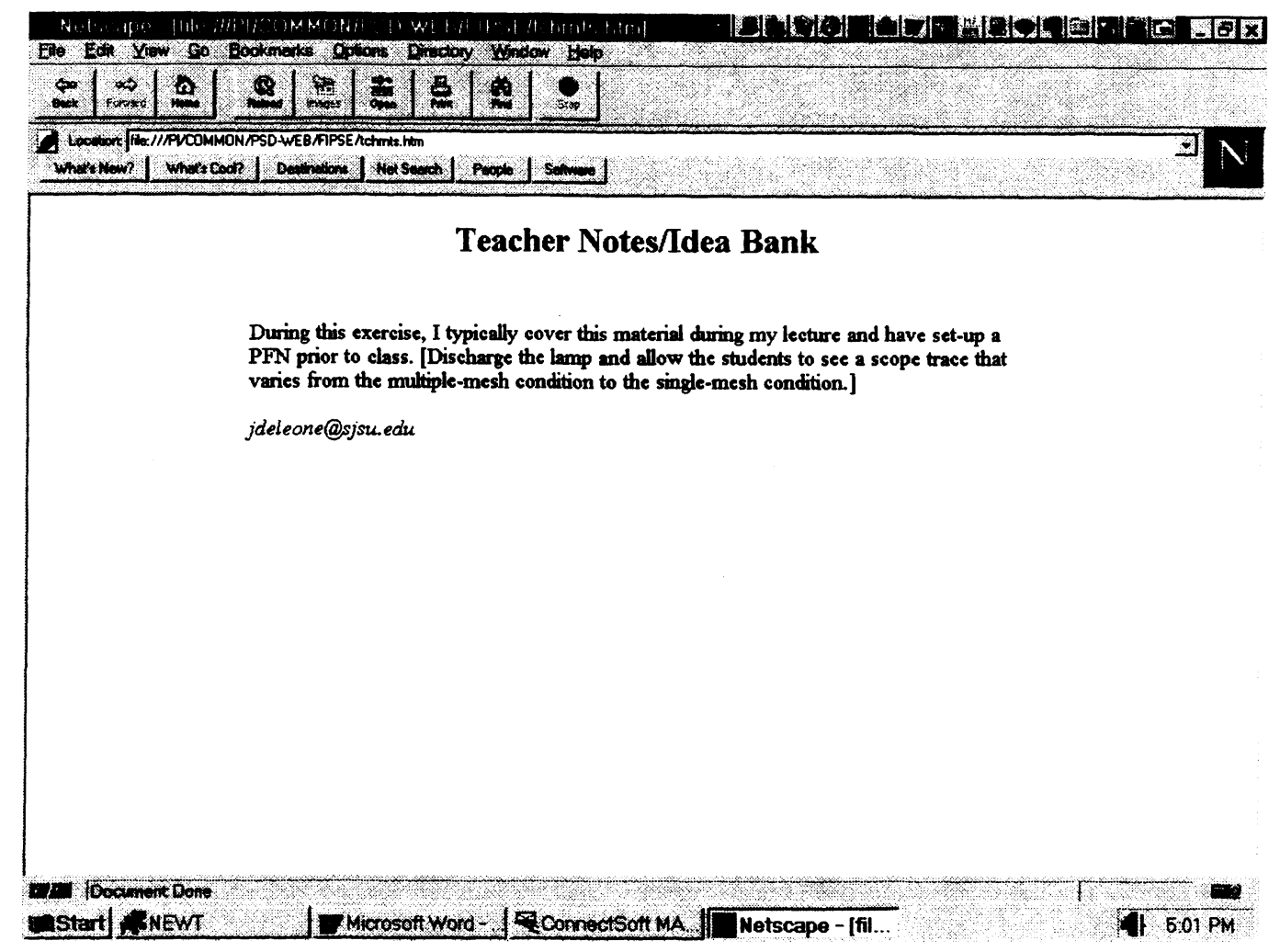

Figure 5. Web page illustration 3

\section{Limited Case Study}

In an effort to evaluate the validity of the morphing process, a limited case study was conducted in October 1995, at a National Technician Preparation Conference in Atlanta, Georgia. The essential ideas and tasks mentioned above in the morphing process were evaluated in a one-hour session entitled "Curriculum Morphing." The abstract listed in the conference guide explained that the session was a test case for the morphing process. Ten computers were available and were linked to the Internet. One additional computer was placed in the room for use by a four-person "technical review committee." At each computer, four or more participants crowded around so they could see the screen. The group of 25 was handed instructions and the flowchart for the morphing process and given brief instructions on the process. Participants were reminded that this session was a test, and they were encouraged to provide as many useful ideas as possible, with the one caveat being that all ideas should include some sort of solution to the identified problem with the curriculum being morphed, just as would be the case with the morphing process for the photonics curriculum. All participants were educators, involved in grades 9 through 14, including eleven males and thirteen females from 17 states_extending from California to Georgia and from Wisconsin to Texas.

Participants were sequestered in the room with the "technical review committee" (TRC) and instructed that the computers would be their only means of communication with the TRC for approximately 45 minutes. They were asked to examine appropriate text material from a science course that contained all the HTML formatting mentioned above, including illustrations. They were then told to communicate suggested changes to a central computer via an internal network, view modifications to the suggested changes as made by the TRC, and share reaction to the process on a survey form at the conclusion of the session. In addition, participants were asked to extrapolate this exercise to a more general process, placing themselves in their workplace environment and communicating in like fashion to a central computer located in Waco, Texas, using and exchanging information in real time. 
The curriculum did morph, and in fact went through at least eight iterations during the 45-minute time span-a testament to the capability of the morphing process to react quickly to recommendations from the field. Despite the time constraints and "artificial environment" surrounding this limited case study, results were highly favorable. Of the group surveyed at the end of the case study, 78 percent "strongly agreed" and 22 percent "agreed," that "Using the morphing process for curriculum development would help keep materials up-to-date technically." Also, 65 percent "strongly agreed" and 30 percent "agreed" that curriculum morphing would help me feel I am a part of the development of the materials I am being asked to use.

Several members of the group offered cautions about the availability of the necessary technology at local school sites and sufficient faculty time and access during working hours for such an undertaking. However, it is valuable to point out that some of the members of this study were from high schools, and in 1995, Internet access in high schools was considerably less than is access in 1997.

\section{Summary}

The project intends to place over 1900 pages and 1300 illustrations of existing (though outdated) Laser/Electro-Optics curriculum material on a World Wide Web page. With this accomplished and available to interested faculty, a morphing process will be used to revise, update, and broaden the materials to include the latest in photonics technology, i.e., develop a current photonics curriculum. With the initial development complete and accepted by a Technical Review Committee, the morphing process will be extended to modify and update the materials on a continuing basis. The current project allows institutions to share the brightest ideas among faculty to pedagogically improve curricula and instruction nationwide in a manner that cannot be otherwise accomplished without the Internet. At the same time, the curriculum being morphed addresses a critical technology education need, namely the development of a modern photonics curriculum.

\footnotetext{
'In biology, the term morph refers to "a local population of a species that consists of interbreeding organisms." In the present context of curriculum development and ongoing maintenance of technical currency of curriculum, the basic idea of morph is generalized to a morphing process. This involves interaction of faculty via computer through a World Wide Web site, E-mail, and other devices to modify and update technical curricula on an ongoing basis.

2 Angel DePalma. "Photonics: The Technology and Its Potential." Fort Lee, NJ: Technical Insights Inc., 1994, as quoted in "Photonics Technology Will Surpass the Transistor," Optics and Photonics News, May 1994.

3 “Optoelectronic Technology Roadmap: Conclusions and Recommendations," Optoelectronics Industry Development Association, 1994.
} 